\title{
PADRÃO BIOMÉTRICO, MEDIDAS DE ATRELAGEM E ÍNDICE DE CARGA DE EQUIDEOS DE TRAÇÃO URBANA DO MUNICÍPIO DE ARAPIRACA, ALAGOAS
}

\author{
Tobyas M. de Albuquerque Mariz¹, Pierre Barnabé Escodro1, João Ricardo Dittrich², \\ Monique Souza Netoํㅜ, Carolyny Batista Lima1, Julimar do Sacramento Ribeiro \\ 1 UFAL \\ 2 UFPR \\ Correspondência: Tobyas Mariz: tobyasmariz@hotmail.com
}

RESUMO: Milhares de pessoas utilizam a carroça tracionada por equídeos como meio de trabalho ou suplementação de renda no âmbito mundial. Poucas são as pesquisas envolvendo a caracterização biométrica dos animais e as medidas dos equipamentos de atrelagem, buscando classificar os equídeos pela capacidade de tração, propondo discussões cientificamente embasadas acerca da capacidade de carga por animal, consequentemente diminuindo os maus tratos e dimensionando o trabalho de forma proporcional e coerente. Objetivou-se determinar parâmetros zoométricos ligados a ezoognósia, caracterizando tipologia e medidas relacionadas à veículos de atrelagem de 234 equídeos de tração no município de Arapiraca-Alagoas, Brasil. Foram obtidas medidas morfoestruturais lineares e perimetrais, calculando-se os índices zoométricos: índice corporal, peso estimado, índice dáctilo-torácico, índice de carga a passo e índice de carga a galope. Os dados foram submetidos a uma análise de variância e teste de médias (Skott-Knott a $5 \%$ de probabilidade). Os muares representaram $76 \%$ (179) dos animais estudados, os equinos $21 \%$ (49) e os asininos 3\% (6). Em todas as medidas morfoestruturais e índices zoométricos, com exceção do índice corporal onde os asininos apresentaram a maior média, verifica-se diferença $(P<0,05)$ entre as espécies com os equinos sempre apresentando maiores valores, seguidos pelos muares e asininos. Não há adequação em relação às medidas das atrelagens, verificando-se diferença estatística $(\mathrm{P}<0,05)$ apenas para os veículos tracionados por asininos. Os equinos e muares utilizados por condutores de carroças são classificados como equídeos de pequeno porte, com propensão à tração leve.

Palavras-chave: carroça; equídeos urbanos; índices; medidas

\section{BIOMETRIC STANDARD, WAGON MEASURES AND LOAD INDEX OF URBAN CART EQUIDS OF ARAPIRACA CITY, ALAGOAS}

\begin{abstract}
Thousands of people use the cart pulled by horses as a means of work or supplemental income in the world. But there are few studies involving the animal biometric characterization and wagon measures, seeking classify equids for traction capacity and propose scientifically sound discussions about the load capacity per animal, thus reducing maltreatment. The aim of this paper was to determine the zoometric standard, typology and wagon measures of the 234 cart equids from Arapiraca city, Alagoas state, Brazil. Morphostructural linear and perimeter measurements were obtained, calculating the zoometric indexes: body index, estimated weight, dactyl-thoracic index, work walking index and work galloping index. The variables were subjected to analysis of variance and means test (Skott-Knott 5\% probability). The mules represented $76 \%$ (179) of the animals, horses $21 \%(49)$ and donkeys $3 \%(6)$. In all measurements and indexes studied, except where the donkeys body index had the highest average, there is a statistical difference $(P<0.05)$ between species with the highest values always with horses, mules and followed by donkeys. There are no adequate in relation to the wagon measures, verifying difference $(P<0.05)$ only for vehicles pulled by donkeys. The horses and mules used by drivers of carts are classified as small equids, with a propensity to a slight traction.
\end{abstract}

Key words: indexes, measures, urban equids, wain 


\section{INTRODUÇÃO}

Os equídeos foram os principais animais responsáveis pela expansão produtiva e geográfica humana, principalmente devido à condição de gerador de força motriz, o que permite enquadrá-los em papel produtivo diferenciado, quando relacionado às demais espécies de interesse zootécnico. Atualmente, a equideocultura comercial objetiva a criação e comercialização de animais atletas ou de lazer, porém a utilização de cavalos de tração ainda é o principal elemento para a subsistência de muitas famílias, principalmente nas grandes cidades brasileiras. A sociedade infelizmente associa esta atividade a elementos problemáticos, por considerála subemprego, associá-la à marginalidade e aos maus tratos de animais, devido ao despreparo e desconhecimento dos condutores (Escodro et al., 2010; Jordão et al.,2011).

No entanto, a presença dos carroceiros nos médios e grandes centros urbanos brasileiros é crescente, fazendo emergir a necessidade da elaboração de leis municipais para normatizar a atividade em moldes aceitáveis para a maioria da população. Estas ações quase sempre tratam da identificação do veículo e do condutor por meio de placas e carteiras de habilitação (Souza, 2006; Oliveira et al., 2007), porém não consideram avaliações zoométricas e capacidade de carga individual dos animais. $O$ conhecimento aprofundado do conjunto que compõe este módulo de tração e transporte é essencial na implementação de futuras normatizações, considerando como foco central o equídeo e o bem estar animal.

As carroças tracionadas por equídeos no Brasil são normalmente compostas por uma área de lastro suportada por um único eixo adaptado a rodas com pneus. A ligação com 0 animal é feita por meio de dois componentes de madeira que se pronunciam a frente do lastro, conhecidos comumente como braços da carroça, ligando-se ao selote no dorso do animal e a coalheira que fica em seu pescoço. São, portanto voltadas para o transporte de cargas, assemelhando-se ao tradicional modelo eslavo desse veículo e diferindo das charretes e carruagens, que se prestam ao transporte de pessoas.

A classificação tipológica de um equídeo, quanto a sua aptidão para determinado trabalho, pode ser feita através de análises das relações existentes entre diversas medidas corporais do animal (Astiz, 2009). No Brasil a avaliação desses parâmetros biométricos e a classificação de equinos carroceiros já foram realizadas recentemente na cidade de Pelotas por Paz et al. (2013), sendo que os mesmos concluíram que os animais são inadequados para o trabalho de tração com cargas pesadas. $O$ presente trabalho buscou avaliar o padrão biométrico dos animais utilizados na cidade de Arapiraca em Alagoas, a segunda mais populosa do Estado e com mais de quinhentos carroceiros cadastrados na prefeitura municipal. Adicionalmente aos índices avaliados por Paz et al. ( 2013) nos cavalos de Pelotas, a pesquisa também calculou os índices de carga no dorso a passo e a galope por espécie (equino, asinino e muar), além de mensurações específicas associadas à atrelagem, criando subsídios para futuras pesquisas de avaliação de capacidade de carga puxada na carroça por animal. 


\section{MATERIAL E MÉTODOS}

A pesquisa foi realizada em 234 equídeos e seus veículos utilizados para tração animal na zona urbana do município de Arapiraca-AL. Inicialmente, cada animal foi classificado de acordo com a espécie (equina, asinina e muar) e respectivo sexo (macho e fêmea). A idade aproximada foi identificada por avaliação da arcada dentária, segundo Richardson (1997) e Silva et al. (2003). As medidas zoométricas e da respectiva atrelagem foram identificadas com o uso de hipômetro e fita métrica. Os índices corporais foram calculados a partir destas medidas.

As medidas morfoestruturais aferidas (Figura 1) foram à altura de cernelha (AC), correspondente ao ponto mais alto da região interescapular, até o solo; altura de garupa (AG), partindo do ponto mais alto da tuberosidade sacral do íleo até o solo; comprimento corporal (CC), traçado entre o tubérculo maior do úmero e a tuberosidade isquiática; comprimento de garupa (CG), traçado entre a asa do íleo e a tuberosidade isquiática; largura de garupa nos íleos (LGil), medida entre as asas dos íleos; largura de peito (LP), distância entre as bordas laterais das articulações escápulo-umeral direita e esquerda; profundidade de tórax (ProT), distância vertical entre o ponto mais alto da região interescapular e a cartilagem xifoide de forma perpendicular ao solo; perímetro torácico (PerT), circunferência do tórax traçada na linha da apófise espinhosa da $7^{\mathrm{a}}-8^{\mathrm{a}}$ vértebra torácica até a região esternal inferior correspondente, à nível da tuberosidade do olecrano; e perímetro de canela (PerC), aferida pela circunferência do osso metacárpico esquerdo em seu terço médio.

Os índices corporais calculados foram a Massa Corporal (MC), produto do perímetro torácico elevado ao cubo pela constante 80; o Índice Corporal (ICorp), relação entre o produto da medida do comprimento corporal com a constante 100 e o perímetro torácico; o Índice de Proporcionalidade (IProp), divisão do produto entre a medida da altura de cernelha com a constante 100 , pelo comprimento corporal; o Índice de Conformação (IConf), relação entre o perímetro torácico e a altura da cernelha; o Índice de Compacidade (IComp), relação entre peso corporal e altura de cernelha; o Índice dáctilotorácico (Idt), relação entre o perímetro da canela e o perímetro torácico; Índice de Carga no Dorso a Passo (ICp), relação entre o produto do perímetro torácico elevado ao quadrado com a constante 98 e a altura da cernelha; Índice de Carga no Dorso a Galope $(\mathrm{ICg})$, dado pela relação entre o produto do perímetro torácico elevado ao quadrado com a constante 56 , e a altura da cernelha. Os indivíduos foram classificados em longilíneo (Índice Corporal superior a 90, trabalho em velocidade), mediolíneo (entre 86 e 88 , trabalho intermediário) e brevilíneo (inferior a 85, trabalho de força), de acordo com Astiz (2009).

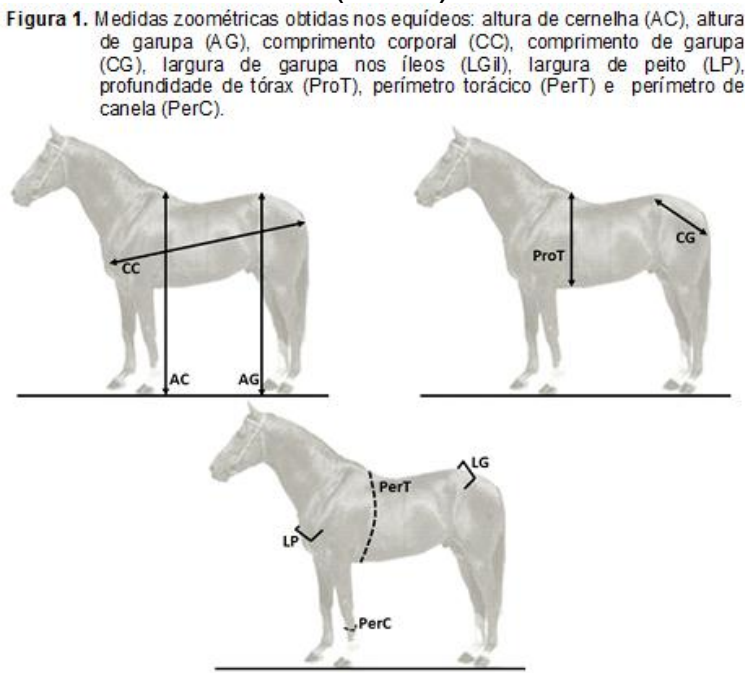

As medidas aferidas na atrelagem (Figura 2) foram a altura do braço da carroça no ponto de ligação ao animal $(\mathrm{H} 1)$, altura do braço da carroça no ponto de origem no veículo (H2), altura 

urbana do município de Arapiraca, Alagoas

do lastro da carroça na linha perpendicular do eixo da roda $(\mathrm{H} 3)$, altura do lastro da carroça no ponto final do veículo $(\mathrm{H} 4)$, comprimento do braço da carroça (CBcar) e comprimento do lastro da carroça (CLcar).

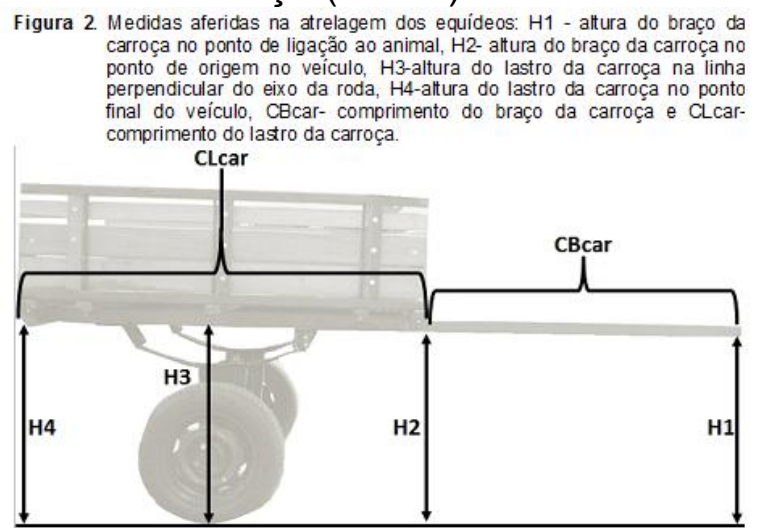

Os dados foram submetidos a uma análise de variância e teste de médias (Skott-Knott a 5\% de probabilidade) para estabelecer a relação entre as medidas coletadas entre as espécies estudadas (asininos,equinos e muares). O programa estatístico utilizado foi 0 SISVAR.

\section{RESULTADOS E DISCUSSÃO}

A classificação tipológica dos 234 equideos avaliados, de acordo com a espécie, apresentou $76 \%$ de muares, $21 \%$ de equinos e $3 \%$ de asininos e permitiu identificar a expressiva preferência dos proprietários pela primeira classe em questão (Tabela 1).

A justificativa apresentada é que os muares apresentam-se mais resistentes à jornada de trabalho. A menor utilização de asininos está muito mais associada à falta de oportunidade de possuir um equino ou muar, do que propriamente a uma escolha. Apenas em dois estudos, o número de asininos empregados no trabalho de tração de carroças foi superior ao de equinos e muares (Alves et al., 2009; Chaves et al., 2011). Assim, os jumentos são preferencialmente utilizados como reprodutores na produção de muares, condição que os valoriza como reprodutores e incrementa a comercialização de híbridos (muares) destinados à tração. Estudos realizados em outros centros urbanos relatam que os equinos e os muares também são preferidos como animais de tração (Maranhão et al., 2006; Andrade et al. , 2009; Paz et al., 2010; Lima et al., 2011).

A classificação por sexo apresentou expressiva predominância de fêmeas em relação aos machos, todos castrados, independente se entre os muares, equinos ou asininos (Tabela 1 ). Do total de animais avaliados 32 $(13,68 \%)$ eram machos e 202 (86,32\%) eram fêmeas.

\begin{tabular}{|c|c|c|c|c|}
\hline Espécie & Total & $\begin{array}{l}\text { Idade do plantel } \\
\text { e desvio padrão }\end{array}$ & Sexo & $\begin{array}{l}\text { Idade entre sexos e } \\
\text { desvio padrão }\end{array}$ \\
\hline \multirow[b]{2}{*}{ Muares } & \multirow[b]{2}{*}{179} & \multirow[b]{2}{*}{$9,4 \pm 5,3$} & 13 machos & $7,6 \pm 3,1$ \\
\hline & & & 166 fêmeas & $9,5 \pm 4,6$ \\
\hline \multirow{2}{*}{ Equinos } & \multirow{2}{*}{49} & \multirow{2}{*}{$8,3 \pm 3,2$} & 18 machos & $8,4 \pm 3,8$ \\
\hline & & & 31 fêmeas & $8,3 \pm 2,9$ \\
\hline \multirow[b]{2}{*}{ Asininos } & \multirow[b]{2}{*}{06} & \multirow[b]{2}{*}{$9,0 \pm 4,0$} & 1 macho & 5,0 \\
\hline & & & 5 fêmeas & $9,8 \pm 4.0$ \\
\hline
\end{tabular}

A preferência por fêmeas é devido ao fato delas serem também para a reprodução, no caso das éguas, e pelo temperamento mais calmo o que facilita 0 trabalho de tração. Este temperamento também é apresentado por cavalos castrados, mas a castração envolve custos e impossibilita o trabalho dos animais por determinado período. Outro fator importante na escolha de fêmeas é que não precisam parar de tracionar as carroças para urinar, fato este que dificulta o uso de machos devido às paradas não programadas em locais de trânsito intenso. A marcante predominância de fêmeas muares $(92,73 \%)$ encontrada nesta classificação também foi identificada em outros centros (Lima et al., 2011), o que reforça as razões já apresentadas para utilização desse tipo de animal nas trações urbanas. Entre os equinos avaliados o percentual de fêmeas foi de 
$63,27 \%$, valor que contrasta com a predominância de fêmeas muares, mas demonstra, como em outros trabalhos (Paz et al., 2010; Lima et al., 2011), que para a espécie equina o sexo não é um fator preponderante na escolha de animais de tração. $O$ pequeno número de asininos classificados não permite maiores conclusões na escolha do sexo para tração urbana nesta espécie.

A análise das medidas morfoestruturais dos animais utilizados para tração urbana permite identificar diferenças $(P<0,05)$ entre as espécies, onde os equinos apresentam maiores medidas, seguidos pelos muares e asininos (Tabela 2). Espera-se que os animais que apresentam maiores medidas corporais acabem por suportar maiores cargas, uma vez que apresentarão maiores proporções corporais que culminam por aumentar a força de tração do indivíduo. Esta resposta verificada na Tabela 2 não está associada à preferência dos proprietários entre as espécies, pois os muares são encontrados em maior número (Tabela 1).

Por outro lado, identifica-se associação entre as menores medidas morfoestruturais dos asininos e a não utilização desta espécie em larga escala na atividade. $O$ menor porte identificado nos asininos pode ser melhorado, pois de acordo com Torres e Jardim (1977), existem raças de jumentos como a Pêga, a Paulista, as raças Italianas e as Espanholas, que atingem $135 \mathrm{~cm}$ de cernelha ou mais, mas a prevalência da raça Jumento Nordestino, também descrito por esses mesmos autores, é marcante no Nordeste brasileiro, caracterizando-se por animais de menor porte $(0,90$ a $1,10 \mathrm{~m}$ de $A C)$, mas que por sua rusticidade servem para carga em lombo e montaria nas zonas rurais da região. Paz et al. (2010), avaliaram o padrão zoométrico de equinos de tração no município de Pelotas - RS, e relataram médias gerais de $138 \mathrm{~cm}$ para altura de cernelha e $19 \mathrm{~cm}$ de perímetro de canela, que são maiores que os encontrados nesse estudo, e de $26 \mathrm{~cm}$ de largura de peito e $149 \mathrm{~cm}$ de perímetro torácico, esses por sua vez menores que as médias verificadas nos equinos de tração.

A falta de outros estudos zoométricos em muares de tração impossibilita a comparação dos dados obtidos, mas estes animais representam a preferência dos proprietários mesmo apresentando medidas morfoestruturais intermediárias entre equinos e asininos, o que reforça a rusticidade como fator decisivo na escolha do animal destinado a tração urbana. Outro ponto a ser ressaltado é a informação da utilização dos asininos como reprodutores na obtenção de muares, fato este que pode direcionar a seleção de reprodutores com medidas morfoestruturais maiores para esta finalidade.

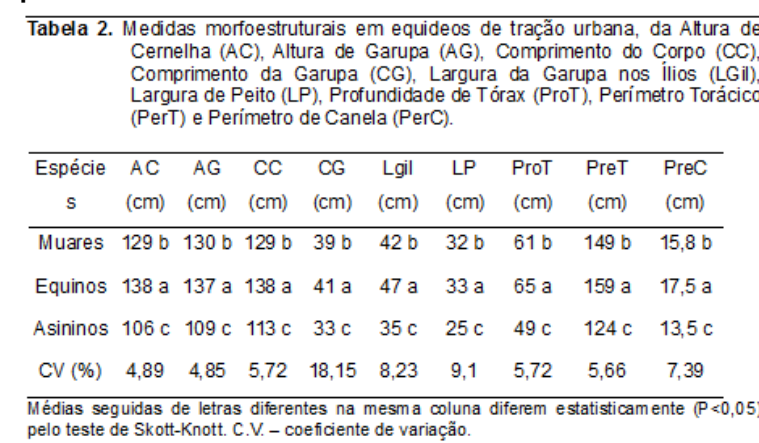

Torres e Jardim (1977) afirmam que com a seleção criteriosa de jumentos e éguas, os muares produzidos serão tão grandes ou muitas vezes maiores que equinos de mesma genética materna, dando ótimos animais para o trabalho. Ainda segundo esses autores, o maior porte possibilita uma maior capacidade de trabalho de tração, mas enquanto se reservarem as piores éguas e as piores condições de manejo para produção de muares, não será alcançado bons resultados. Vale ressaltar, contudo, que as exigências nutricionais de mantença e produção também aumentam em indivíduos maiores, o que dependendo das 
condições de criação pode se tornar um problema.

Nos resultados dos índices corporais (Tabela 3), observa-se que o padrão de resposta foi semelhante ao ocorrido nas medidas morfoestruturais, pois os equinos apresentaram índices corporais superiores, seguido pelos dos muares e asininos. A exceção foi 0 índice corporal (ICorp) dos asininos, superior aos dos equinos e muares. Este índice classificou os asininos como animais longelíneos (superior a 90, trabalho em velocidade) e os equinos e muares como mediolíneos (entre 86 e 88, trabalho intermediário), baseado na classificação de Astiz (2009). Assim, todos os animais avaliados não possuem índice corporal adequado para o trabalho de tração, propriamente dito, - que leva a refletir a respeito da capacidade de carga na atrelagem utilizada por estes indivíduos.

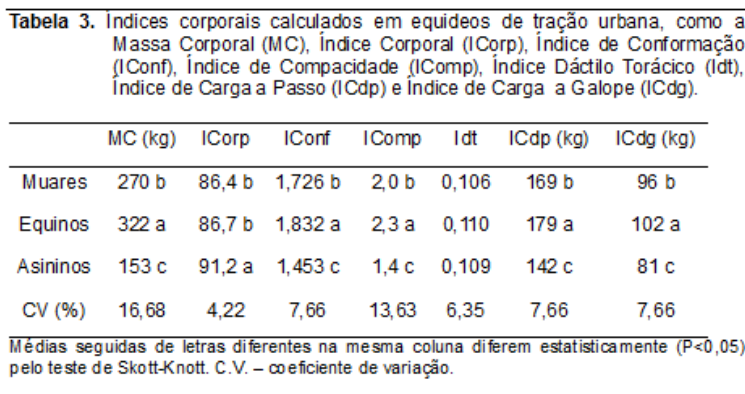

Em relação à massa corporal (MC), as três espécies representam animais pequenos ou hipométricos, por estarem abaixo de 350 kg (Astiz, 2009). Animais hipométricos também foram descritos em outros estudos, como por Paz et al. (2010) que observaram que o peso médio de equinos de tração do município de Pelotas - RS foi de $321 \mathrm{~kg}$, valor bem próximo ao verificado nos equinos desse estudo. Lima et al. (2011), analisando equídeos de tração em dois municípios de Alagoas, verificaram em Quebrangulo média de $178,6 \mathrm{~kg}, 293 \mathrm{~kg}$ e $281,53 \mathrm{~kg}$, e em Santana do Ipanema médias de 151,7 $\mathrm{kg}, 263,4 \mathrm{~kg}$ e 219,6 kg, para asininos, equinos e muares, respectivamente.
O índice de conformação (Iconf) ficou abaixo de 2,0 (dois) o que enquadra todos os animais desse estudo, independente da espécie, como animais de aptidão para sela, pois os de tração devem apresentar valor acima de 2,1125 (Torres e Jardim, 1977). Paz et al. (2010) relataram valor médio para o índice de conformação de equinos de tração do município de Pelotas - RS de 1,763 , ainda menor do que o verificado par os equinos desse estudo. $O$ melhoramento genético é uma ferramenta indispensável na obtenção de animais com índices de conformação adequados aos trabalhos de tração. Pérez, et al. (1993), verificaram que mais de $96 \%$ dos animais oriundos de cruzamentos com raças próprias para tração apresentaram índice de conformação acima de 2,1125, o que demonstra a alta herdabilidade desta característica.

Os índices de compacidade (IComp) confirmam, mais uma vez, a tipologia característica de animais para sela, pois para serem enquadrados pelo menos como de tração leve, deveriam alcançar valores correspondente a 2,75, e superiores a 3,15 para considerar-los como de tração pesada (Astiz, 2009). Esta característica também foi observada nos estudos de Paz et al. (2010), no município de Pelotas - RS.

O índice dáctilo-torácico (Idt) foi o único que não apresentou diferença $(P>0,05)$ entre as espécies (Tabela 3). Os muares deste estudo são enquadrados como animais leves, os asininos como intermediários e os equinos como de tração ligeira, de acordo com a tipologia descrita por Torres e Jardim (1977). Esta analise confirma a estrutura inadequada destes animais para tração pesada, pois para tal finalidade deveriam possuir um ldt superior a 0,115 (Torres e Jardim, 1977).Em relação aos dois Índices de Carga no dorso a passo e a galope 
(ICdp e ICdg), os valores encontrados mostram maior capacidade de carga para os equinos, seguido dos muares e asininos (Tabela 3). A análise destes índices permite estimar a capacidade de carga de equídeos utilizados por carroceiros, porém não servem ainda como índices de controle de limite de peso tracionado por esses animais, pois referem-se ao peso a ser carregado no dorso e não na carroça.

De acordo com Souza (2006) e Oliveira et al. (2007), o excesso de peso no trabalho é o principal fator causador de danos à higidez sanitária dos animais e merece atenção especial para que os agentes humanos e animais envolvidos possam conviver bem e continuar produzindo juntos. Estudos que contemplem o desenvolvimento de uma equação de capacidade de carga para equídeos de tração de carroças precisam ser desenvolvidos a fim de preencher essa lacuna de informação e contribuir com a normatização desse tipo de atividade.

Os resultados das medidas das carroças são apresentados na Tabela 4, nota-se diferença $(P<0,05)$ apenas para os veículos tracionados por asininos, estando os de equinos e muares dentro de um aparente padrão local.

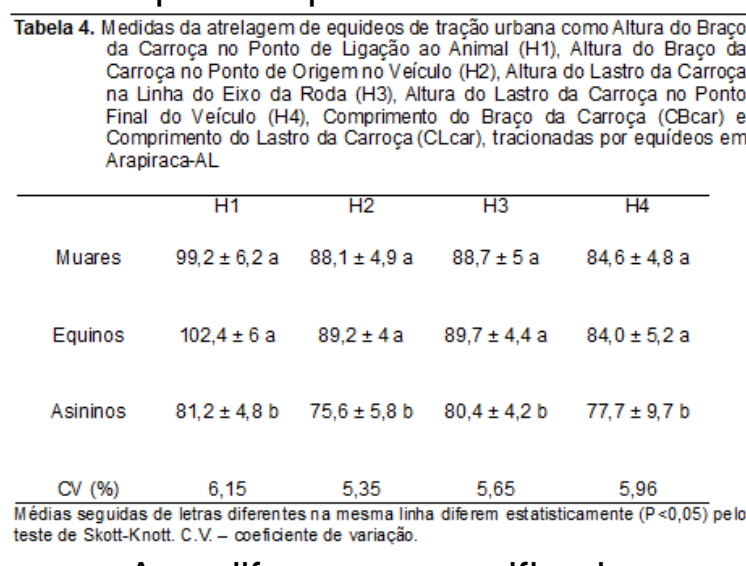

A diferença verificada nos veículos tracionados por asininos existe devido a grande diferença morfoestrutural presente entre os animais dessa espécie e das demais avaliadas nesse estudo, tão grande que os impossibilita de tracionar carroças com as medidas usadas por equinos e muares. Contudo, também é preciso considerar que existem diferenças tipológicas entre os equinos e muares analisados, e que isso deveria ser considerado individualmente quando da adequação da carroça as características zoométricas de cada animal.

Tomando por exemplo a medida $\mathrm{H} 1$, que trata da altura do braço da carroça no ponto de ligação do veículo junto ao animal, que fica em um selim colocado no dorso lombo do animal, não se verifica diferença estatística $(P>0,05)$ entre os dados de equinos e muares, mas ao remetermos a Tabela 1, nota-se que em todas as medidas de altura tomadas, seja de cernelha ou de garupa, existe diferença significativa $(P<0,05)$ entre essas espécies. Isso mostra que as adequações dos veículos as condições tipológicas individuais são necessárias, mas novamente isso só será possível após o desenvolvimento de pesquisas que contemplem a otimização do trabalho de tração de carroças por equídeos.

\section{CONCLUSÃO}

Os equinos e muares representaram a maior parte dos animais utilizados na tração de carroças na área urbana de Arapiraca. A partir das medidas aferidas e índices zoométricos calculados, conclui-se que a estrutura corporal dos animais avaliados é inadequada para tração, exteriorizando inaptidão para a função.

Ainda não há adequação dos veículos tracionados à estrutura zoométrica dos equídeos utilizados nessa atividade, havendo a necessidade de novas pesquisas, que a partir das medidas dos animais e atrelagem, iniciem o desenvolvimento de solução ou fórmula para cálculo de carga por animal, diminuindo os maus tratos aos animais. 
Padrão biométrico, medidas de atrelagem e índice de carga de equideos de tração urbana do município de Arapiraca, Alagoas

\section{NOTAS INFORMATIVAS}

\author{
Aprovado CEUA/UFAL sob Protocolo
} no 007/2012.

\section{REFERÊNCIAS}

ALVES, F.R.; GUERRA, P.C.; FIORETTO, E.T. et al. Angiographic aspecto $f$ the distal forelimb in donkeys (Equus asinus) used for animal traction. Revista Biotemas, v.22, n.4, p.163$167,2009$.

ANDRADE, R.L.F.S.; SOBRAL, J.C.; SILVA, K.M.G. Avaliação clínica, hematológica e parasitária em equinos de tração na cidade de Aracaju, Sergipe. Acta Veterinaria Brasilica, v.3, n.3, p.138-142, 2009.

\section{ASTIZ, C.S. Valoración morfológica de los} animales domésticos. Ed. Ministerio de Medio Ambiente y Medio Rural y Marino-España. 2009. $864 \mathrm{p}$.

CHAVES, N.P.; BEZERRA, D.C.; GUERRA, P.C et al.. Lesões podais em asininos (Equus asinus) utilizados em veículos de tração animal na cidade de São Luís, Maranhão. Ciência Animal Brasileira, v.12, n.2, p.365-370, 2011.

ESCODRO, P.B.; TONHOLO, J.; FERNANDES,T.J. et al. Projeto Carroceiro em Alagoas: Empreendedorismo e Inovação no Ensino de Medicina Veterinária e Potencial Multidisciplinar-Resultados Preliminares.

Revista Brasileira de Medicina Equina, v.30, p.26-32, 2010.

JORDÃO, L.R.;FALEIROS,R.R.;AQUINO NETO,H.M. Animais de Trabalho e aspectos éticos envolvidos: Revisão Crítica. Acta Veterinaria Brasilica, v.5, n.1, p.33-40, 2011.

LIMA, E.S.; ESCODRO, P.B.; MARIZ, T. M.A. et al. Perfil zootécnico dos equídeos de tração atendidos na cidade de Quebrangulo e Santana do Ipanema pelo projeto Carroceiro Vet legal em 2011. In: VIII CONGRESSO ACADÊMICO DA UNIVERSIDADE FEDERAL DE ALAGOAS. 2011. Maceió. Anais... Maceió, 2011.

MARANHÃO, R.P.A.; PALHARES, M.S.; MELO, U.P. et al. Afecções mais freqüentes do aparelho locomotor dos eqüídeos de tração no município de Belo Horizonte. Arquivo Brasileiro de Medicina Veterinária e Zootecnia, v.58, n.1, p.21-27, 2006.
OLIVEIRA, L.M.; MARQUES, R.L.; NUNES, C.H et al.. Carroceiros e eqüídeos de tração: um problema sócio-ambiental. Caminhos de Geografia, v.8, n.24, p.204-216, 2007.

PAZ, C.F.R.; OLIVEIRA, D.P.; PAGANELA, J.C. et al.. Padrão biométrico dos cavalos de tração do município de Pelotas no Rio Grande do Sul. In: XI CONFERÊNCIA ANUAL DA ABRAVEQ. 2010. São Paulo. Anais... São Paulo, 2010.

PAZ, C.F.R.; PAGANELA,J.C.;OLIVEIRA,D.P. et al. Padrão biométrico dos cavalos de tração da cidade de Pelotas no Rio Grande do

Sul.Ci.anim.Bras., v.14, n.2,p.159-163, 2013.

PÉREZ, R.F.; CABEZAS, I.A.; GUZMÁN, R.S.M. et al. Comparación de características hipométricas de caballos mestizos mescendientes de potros fina sangre y criollos de tiro. Avances en Ciencias Veterinarias, v.8, n.2, p.1-9, 1993.

RICHARDSON, J. Ageing Horses - An ilustrated guide. In Practice, p.486-489, 1997.

SILVA, M.F.; GOMES,T.; DIAS,A.S. et al. Estimativa da idade dos equinos através do exame dentário. RPCV, v.98, n.547, p.103-110, 2003.

SOUZA, M.F.A. Implicações para o bem-estar de equinos usados para tração de veículos. Revista Brasileira de Direito Animal, v.1, n.1, p.1-6, 2006.

TORRES, A.P.; JARDIM, W.R. Criação do cavalo e de outros equinos. Ed. Nobel. 1977. $654 \mathrm{p}$ 